\title{
Impact of Quality Human Resource in Health Care Providing Organizations
}

\author{
Muhammad Asif Khan
}

\begin{abstract}
The management of human resources in health-care institution is essential to enable the delivery of efficient and effective medical services and to achieve patient satisfaction. This study aims to investigate how the impact of new technological innovation in health / medical sciences and patient care put an effect on the performance of the health-care providing institutions and to analyze how these innovations are putting an impact on performance of the health-care related human resource (employees) and that up to what extent despite of these rapid technological changes, the practicing human resources management is enable to increase the human resource performance, quality of health-care service and help them out to achieve patients' satisfaction. The exploratory methodology was applied to demonstrate and analyze the previous literatures. The study shows that effective human resources management has a strong impact on health-care quality and improving the performance of hospital's staff. The study suggests before starting performance development process as well as continuous development and training of staff performance, there is a need to measure the performance of the managers of human resources department in the health-care organizations. The purpose of this research study is to gain a deeper understanding of the impact of human resources (employees) on health sector reform, the importance of HRM in all aspects of health-care organizations, the positive impact of increased job autonomy on employee outcomes, and the dynamics of employee engagement in health-care. The literature on the link between HR system perceptions and civility towards patients, specific roles for HRM in building shared values that can serve both the care needs of patients and the business needs of health organizations, the complex linkages between employees' perceptions of human resources systems and hospital performance, and the mechanisms through which HRM can enhance patient satisfaction in health care organizations is relevant to this discussion.
\end{abstract}

Keywords: Bank performance, corporate governance, Panel data, Agency theory

\section{INTRODUCTION}

Now a days the Human Resource is considered one of the most vital resource of any organization, in relation with the health-care providing organizations it becomes more important due to the sensitivity of work, because a minor negligence can lead to the human casualty.

Most of the studies related to health-care providing organizations provide us the information that the customers (patients) of the health-care providing organizations are not satisfied with the performance of these organizations because of human resource (employees) performance or due to the unavailability of modern medical equipment in these organizations. The sensitivity of the work and the importance of the health-care providing organizations and the low performance of the human resource (employees) reported by different sources

in these organizations has brought me to identify the causes and reasons that directly or

\footnotetext{
${ }^{1}$ MAS after PGDPA from Department of public administration, University of Karachi.

\begin{tabular}{llll|l}
\hline JISR-MSSE & Volume 14 & Number 1 & Jan-June 2016 & 43
\end{tabular}
}


indirectly affect the human resource (employees) performance.

The basic purpose of the research study is to analyze and investigate, how and up to what extent, these two variables, human resource and new technology, are affecting the overall performance of these organizations and to find out that which one is the least or most contributor in the overall performance of the health-care providing industries / organizations.

The research has been carrying out to fulfill the following objectives:

n To evaluate and analyze the impact of quality human resource on health-care providing organizations.

n The ultimate objective is to enhance the credibility, performance and efficiency of the health-care providing organizations / industries.

n Another objective is to identify the ways to maximize the human contributions in the overall performance of the health-care providing industries / organizations.

It is critical to provide clear distinction between these two important inputs, those have direct influence on the health-care providing organizations credibility and performance, but their relationship can be described among them.

Ho: The capability of human resource (employees) has a direct impact on the services rendered by the health-care providing industries / organizations.

HA: The capability of the human resource (employees) has minimal or no impact on the services rendered / provided by the health-care providing industries / organizations as compare to the new technology or innovations related to the health / medical sciences.

The research is based on two variables and tries to explore the importance of these variables

Fig. 1

Human Resources

New Technology

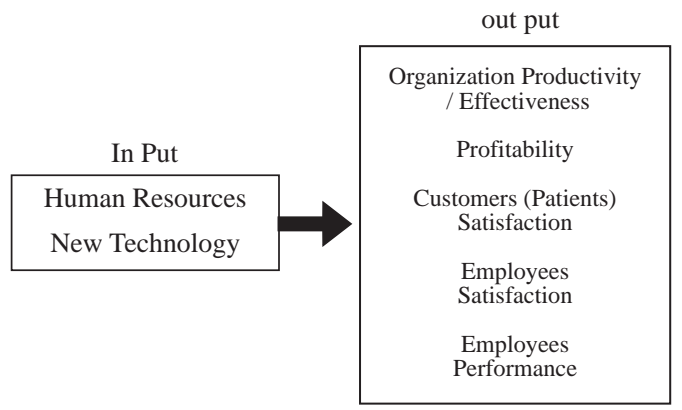




\section{METHODOLOGY}

Following methodology has been applied to analyze the data and to investigate the hypotheses. For the purpose of this research study we can define the applied methodology as follow:

The objective of exploratory research is to gather preliminary information that will help to define problems and suggest hypotheses. Exploratory research is a research conducted for a problem that has not been clearly defined. It often occurs before we know enough to make conceptual distinctions or posit an explanatory relationship. Exploratory research helps determine the best research design, data collection method and selection of subjects. It should draw definitive conclusions only with extreme caution. Given its fundamental nature, exploratory research often concludes that a perceived problem does not actually exist.

The data for this research study has been collected \& explored through secondary sources, which includes following:

n Literature Review

$n$ Extraction of relevant material from the Books related to the health care services

n Past Research Analysis related to the same topic

n Information gathered from medical science journals.

\section{LITERATURE REVIEW}

A brief look at the evolution of quality in modern health care systems may help to understand the need to improve performance measurement. More than 30 years ago, a physician named Avedis Donabedian proposed a model for assessing health care quality based on structures, processes and outcomes. The proposed Donabedian's Model is given as under:

\section{Donabedian's Model}

This framework consists of improving the quality of care into three fundamental parts of healthcare:

Fig. 2

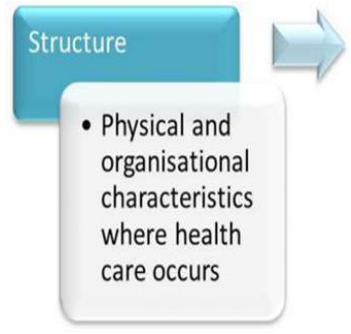

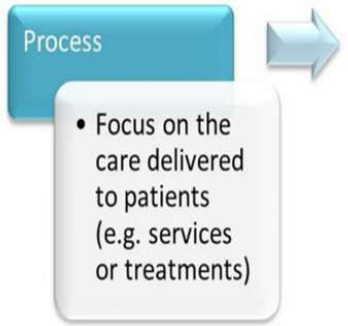

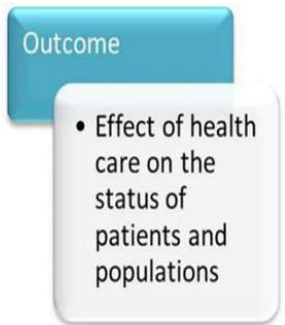

He defined structure as the environment in which health care is provided, process as the method by which health care is provided and outcome as the consequence of the health care provided. As a result, process management is limited, and often temporary, when the structure isn't also improved. Two decades later health care adopted continuous quality improvement, which uses teams to improve processes. According to Donabedian's mode, processes are

\begin{tabular}{llll|l}
\hline JISR-MSSE & Volume 14 & Number 1 & Jan-June 2016 & 45
\end{tabular}


constrained by the structures in which they operate. To date, few health care organizations have addressed these structures because health care senior managers have replicated the behavior of most industrial senior managers by focusing on the process level. This model can be used to categories quality indicators and frame the outcomes of an EBP (Employee Benefit Program) implementation program.

An additional impetus for health care organizations to adopt quality principles has been the Joint Commission on Accreditation of Health-care Organizations' standards. While the JCAHO standards have evolved during the past decade, swayed in part by the Baldrige criteria, health care organizations have been slow to use this organizational assessment as a way to drive performance improvement. The demand from JCAHO for performance improvement drove many health care organizations to learn as much as possible about continuous quality improvement.

An effective measurement system integrates initiatives, aligns organizational units and resources, and improves performance. Paradoxically, most people select measures before they decide how to use them. While it makes sense to discuss selection and use of measures in that order, the effective order in practice is the reverse.

\section{Organizations need performance measures in three areas:}

To lead the entire organization in a particular direction

To manage the resources needed to travel in this direction

To operate the processes that makes the organization work

Most organizations typically don't use leadership measures. However, many health care organizations have struggled to move beyond their heavy emphasis on financial measures to include leadership measures. With continuous quality improvement entrenched at the process level, these same organizations struggle to better manage their resources because they don't consider the effects of structures. Without an integration of clinical and financial measures, the same organizations will find it nearly impossible to effectively operate the processes they are so keen on improving. To overcome these barriers, organizations need measures for three purposes:

Senior managers are responsible for ensuring that measures exist for these three purposes at the organizational level. These measures can be placed in a cycle to reveal the three phases that organizations with excellent performance go through.

While health care professionals, especially physicians, tend to shy away from leading and managing organizations as businesses, their scientific background gives them one advantage in developing measures and analyzing the results. The approach described here is based on scientific principles of generating hypotheses about cause-and-effect relationships and testing those hypotheses. The leadership part focuses on developing the measures for all three critical cause-and-effect relationships and analyzing the results. The management part focuses on deciding what action to take based on the analysis and then allocating resources to carry out those actions. Following are three actions to effectively lead the organizations: 
Develop measures to build the value-added interdependency

Manage activities, time and quality to strengthen this interdependency

Analyze performance to determine the effectiveness of those measures and management

Fig. 3

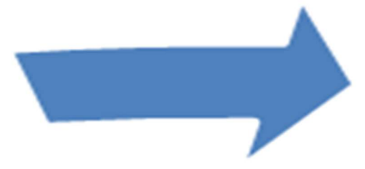

Self Assessment
(Baldrige Criteria)

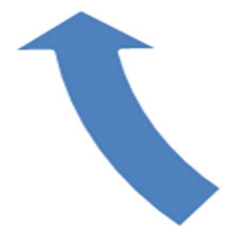

Strategic Planning

(A Balance Scorecard)

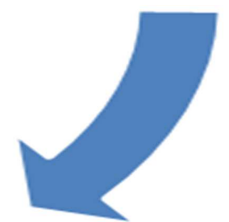

Improving Performance

(Value Based Cost Management)

The popularity of Robert S. Kaplan and David P. Norton's balanced scorecard method-popularized in their book The Balanced Scorecard (1996, Harvard Business School Press)expanded health care organization measures beyond financial analysis. They led to the development of measures in four or more areas, including customers (patients), financial, internal operations and clinical.

The graphic below depicts the Baldrige Framework in terms of what makes it work - its key processes and systems: One argument for looking at the Baldrige Framework with more of a systems perspective is that more than $80 \%$ of the Criteria questions begin with "How". These systems and processes are the enablers of excellence, it's because everything is a process or at least a part of a process. Each process in the Total Baldrige Integrated Excellence System is actually a core process that has been updated using knowledge gained from hundreds of assessments of public and private sector and health care and education Criteria users worldwide. These core processes are the 'best of the best'. However, the best processes in the world are useless unless you can gain their acceptance and implement them. It is much easier to do than most people think. The key to success is to replace the core of your existing processes which are not capable of best-in-class performance with a best practice core processes. This allows you to preserve everything that works well, everything important to your success, your culture, and everything you are already the expert in.

Healthcare organizations need critical performance measures if they lead, manage, and operate effectively. Traditional financial measures or report cards on patient satisfaction and clinical outcomes are insufficient, however value based cost management directly links cost accounting, 
processes, clinical outcomes and patient and employee satisfaction through organizational work, environment and financial measures results.

By understanding how measurements will be used, it becomes easier to understand what measures to have. Measures are needed to test various cause-and-effect relationships at the organizational, process and individual level. By their very existence, organizations create the basis for interdependency among themselves (and partners) and their customers and employees.

This interdependency weakens when one or more parties do not receive value or perceive the value as insufficient. Organizations can strengthen this interdependency by integrating and aligning structures, processes, results, quality and costs. Strengthening the interdependency requires measuring the value each party needs.

Fig. 4

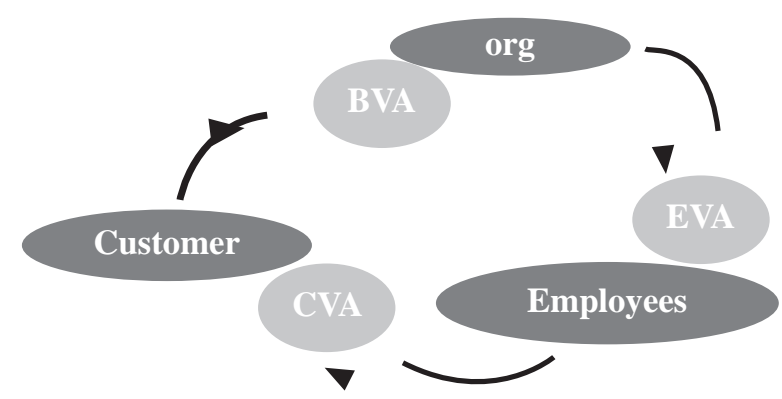

Following standards or indicators can be used to determine the performance or efficiency of the health-care providing organizations / industries. These indicators and the prescribed standards are helpful to gauge the overall performance of the organization after implementing a reform program before introducing a reform program in any health-care providing organization.

The time to health service key performance indicator (KPI) measures health-care providing organization's ability to provide incoming patients with health care service in a timely manner. Prescribed standards to the different health-care services are as under:

\begin{tabular}{ll}
\hline Arrival to Physician & Target 60 minutes \\
Arrival to Bed & Target 20 minutes \\
Arrival to Nurse & Target 40 minutes \\
Arrival to Discharge & Target 100 minutes \\
\hline
\end{tabular}

\section{Lab Turnaround Time}

The lab turnaround time key performance indicators (KPI) measures the ability of the Lab to process lab required results. Prescribed standards of lab turnaround time for different tests are as under:

\begin{tabular}{l|llll}
\hline 48 & Jan-June 2016 & Volume 14 & Number 1 & JISR-MSSE
\end{tabular}




\begin{tabular}{lc}
\hline Lab Test Turn Around & Target Time \\
\hline Amylase & $24 \mathrm{hrs}$. \\
ANA (Antinuclear Antibody) & $168 \mathrm{hrs}$ \\
A PTT (Partial Thromboplastin Time) & $72 \mathrm{hrs}$. \\
Basic Metabolic Panel & $24 \mathrm{hrs}$. \\
Complete Blood Count & $24 \mathrm{hrs}$. \\
Electrotype panel & $24 \mathrm{hrs}$. \\
Comprehensive Metabolic Panel & $48 \mathrm{hrs}$. \\
Sedimentation Rate & $96 \mathrm{hrs}$. \\
\hline
\end{tabular}

Measure the amount of time patients are currently waiting before being seen by a physician in emergency response. The prescribed standards for emergency response are as under:

\begin{tabular}{ccc}
\hline ER & Urgent & Stable \\
\hline Wait Time & $01: 50$ & $02: 30$ \\
\hline
\end{tabular}

\section{Number of Patients in ER:}

Provides key data about patients in the ER such as room number, urgency of their case, current wait time and if they have been attended to by a nurse.

\section{Current ER Occupancy:}

Measures how many are currently occupied in your ER compared to the total number of beds.

Average Length of Safety:

Measures how long on average, patients stay in your hospital after having a specific procedure, such as appendectomy. The prescribed standard for the average length of stay:

\section{Length of stay-------Average 14 days or less}

Other KPIs for Health-Care Providing Organizations:

\section{Inpatient Flow:}

In patient raw mortality rate.

CMS (Centers for Medicare \& Medicaid Services) Core Measure

Harm events per 1000 patients days

Bed turnover

Readmission Rate

Occupancy Rate

Average Cost Per discharge

Patient Satisfaction

\begin{tabular}{llll|l}
\hline JISR-MSSE & Volume 14 & Number 1 & Jan-June 2016 & 49
\end{tabular}




\section{Revenue Cycle:}

Total Operating Margin

Account Receivable (A/R) days due to outstanding

Total Accounts Receivable (A/R) days outstanding

Total Accounts Payable (A/P) days outstanding

Cash receipt to bed debt

Claims Denial Rate

Days of Cash on Hand

\section{The impact of Human Resources on health-Care Providing Organizations}

When examining health care systems, it is both useful and important to explore the impact of human resources on health sector reform taken by any country or a health-care providing organization / institution. While the specific health care reform process varies by country to country and organization to organization, some trends can be identified. Three of the main trends include efficiency, equity and quality objectives.

Efficiency: Various human resources initiatives have been employed in an attempt to increase efficiency. Outsourcing of services has been used to convert fixed labor expenditures into variable costs as a means of improving efficiency. Contracting-out, performance contracts and internal contracting are also examples of measures employed.

Equity: Many human resources initiatives for health reform also include attempts to increase equity or fairness. Strategies aimed at promoting equity in relation to needs require more systematic planning of health services. Some of these strategies include the introduction of financial protection mechanisms, the targeting of specific needs and groups, and re-deployment services. One of the goals of human resource professionals must be to use these and other measures to increase equity in their organizations.

Quality Objectives: Human resources in health sector reform also seek to improve the quality of services and patients' satisfaction. Health care quality is generally defined in two ways:

\section{Technical quality}

Technical quality refers to the impact that the health services available can have on the health conditions of a population.

\section{Socio-Cultural quality}

Socio-cultural quality measures the degree of acceptability of services and the ability to satisfy patients' expectations.

\section{Scientific Management}

Scientific management is based on the work of the US engineer Frederick Winslow Taylor (1856-1915) who in his book The Principles of Scientific Management (1911) laid down the fundamental principles of large-scale manufacturing through assembly-line factories. It

\begin{tabular}{l|llll}
\hline 50 & Jan-June 2016 & Volume 14 & Number 1
\end{tabular}


emphasizes rationalization and standardization of work through division of labor, time and motion studies, work measurement, and piece-rate wages.

Scientific management theory is important because its approach to management is found in almost every industrial business operation across the world. Its influence is also felt in general business practices such planning, process design, quality control, cost accounting, and ergonomics. The knowledge of the theory will give us a better understanding of industrial management. We'll be also ale to understand how a manager can use quantitative analysis, an examination of numbers and other measurable data, in management to improve the efficiency and effectiveness of business operations.

Taylor published accounts of his work in the early 1900s at about the same time as mechanization was being introduced in the industries. This also involves heavily prescribing individual working methods and practices in order to accommodate the new machinery which promised to increase the productivity of every seam in which it was used. Small working groups, often family based, were required to split up and join large shift of men. Job functions were divided between shifts so that each man and each shift was responsible for only one function and therefore whole process was dependent upon each shift completing its allocated function on time.

Current technological advancement in the health services bears eloquent testimony to the fact of organizational change. Not all change has been perceived as unequivocally good. However, where there is a net gain, the organization must learn to absorb the costs. For some workers change can be a painful process and involve jobless and redundancy. In other cases, life-time perceptions of working norms and practices may appear to be discounted, leaving workers emotionally stranded as their careers, together with their knowledge and skills, appear to founder on the rising tide of uncertainty.

The two key areas that Health-Care organizations have to be concern to manage their available staff (human resource) and the available technology (physical resources) to maximize their efficiency and effectiveness to achieve their desire objectives.

How organizations and their managers can, and should, relate to these two main resources of their work has been the concern of Robert Blake and Jane Mouton in their work on The Managerial Grid (Blake R.R. And Mouton J.S.-1985 The Managerial Grid III. Hogan Page.). This is the device for representing the concern for production and for people shown by different mangers with a 1-9 scale being used to represent the degree of concern, 9 representing the high concern. The major points on the Grid and their meaning are shown in Figure below.

\section{Position 9, 1}

Efficiency in operations results from arranging conditions do work in such a way that in such a way that human elements interfere to a minimum degree, by being concerned with acquiring the latest and most efficient technology which itself strictly controls the human input into the work process. This approach may well lead to staff frustration and demotivation (Blake R.R. and Mouton J.S.-1985 The Managerial Grid III. Hogan Page.) through a lack of job satisfaction in feeling themselves to be essentially machine feeders and machine minders.

\begin{tabular}{llll|l}
\hline JISR-MSSE & Volume 14 & Number 1 & Jan-June 2016 & 51
\end{tabular}




\section{Position 1, 9}

This is the opposite approach where the thoughtful attention of the manager to the needs of this staff for satisfying relationships leads to a comfortable, friendly organization atmosphere and working tempo, but whilst job sanctification and morale may be high, production may well not be as efficient as it could and should be. The danger is that more ruthless employers and managers of the 9,1 type will produce the same work at quicker rate and lower cost and that the pleasant, cushioned surroundings created by the 1,9 manger will only be short-term before bankruptcy and redundancy take place.

Fig. 5

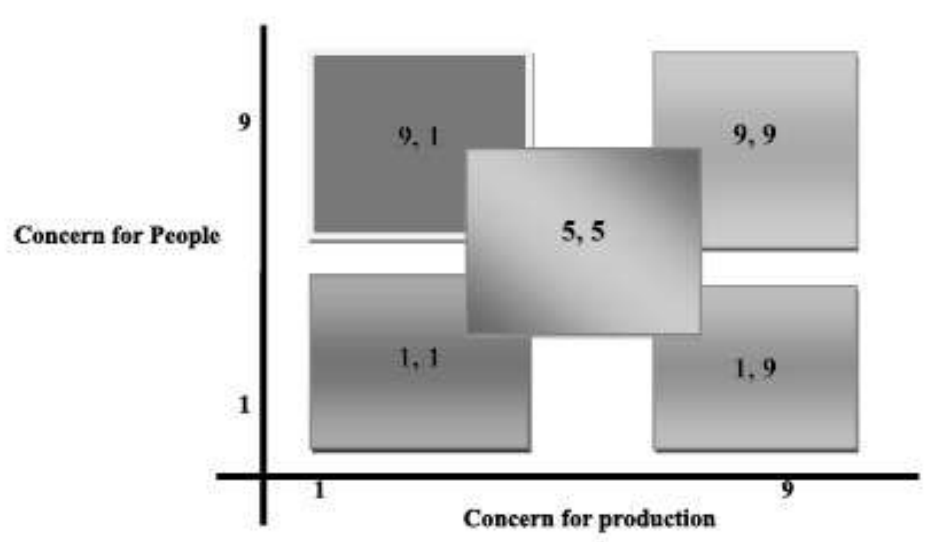

\section{Position 1, 1}

This is the least satisfactory approach of all, where the manger puts in the least effort possible, both with regard to his staff and production equipment in order to get the required work done and to sustain organization membership. The aim is purely to keep things ticking over to survive-a minimalist approach. In this situation, both the morale of the staff and the output of work are likely to be low and inefficient, leading to the twin problems of low motivation and uncompetitive production.

\section{Position 5, 5}

This is where an adequate level of performance is achieved through balancing the necessary to get the work out at a level of speed and efficiency which is competitive enough to provide an adequate level of the staff at a satisfactory level. It could be argued that this is the 'satisficing' level suggested by Herbert Simon.

\section{Position 9, 9}

This is the optimum management approach, where work output and accomplishment is achieved through committed, highly-motivated staffs that agree with, and believe in, the

\begin{tabular}{l|lll}
\hline 52 & Jan-June 2016 & Volume 14 & Number 1
\end{tabular}


equal commitment to using the most efficient and productive as possible. The management's attitude to the staff is that they are as important in the production process as the latest technology they work efficiently with, and this also creates an interdependence between management and staff through their feeling of having a 'common stake' in the purpose, objectives and method of the organization, which leads to relationships of trust and respect.

\title{
Observations Regarding Research Topic
}

During my summer internship training program at International Center for Chemical \& Biological Sciences (ICCBS), University of Karachi, I have observed many addressable issues related to HR practices. During my internship I was attached with the Project Office of Dr. Panjwani's Center of Molecular \& Drugs Research (PCMD), an integral part of ICCBS. Before discussing these issues in details, I would like to give brief intro of the organization. ICCBS is multifaceted research organization and developed by the Government of Pakistan with the help of international donor agencies to produce scientists and carryout research in the field of Chemical \& Biological Sciences. From its beginning this organization has been indulged in to different areas related to Biological \& Chemical Sciences besides its academic activities. Following activities of the ICCBS directly related to health-care service:

\author{
n Drug Research \\ n Disease preventions \\ n Diagnostic Services
}

Being a state owned organization the HR practices are followed under the prescribed government rules and regulations. The employees are hired on permanent basis, mostly related to the academics, other all staff has been hired on ad hoc basis or temporary. This employment practice is causing staff dissatisfaction those who has been hired on temporary basis at permanent nature works.

It is no doubt that organization has been certified by many international organizations but this cannot produce the desired results until unless the HR practices will be implemented in true spirit. All procedures are documented but there is no real outcome has been measured against these practices nor it has been observed that before and after effect of these standards on organization efficiency. Employee satisfaction is main cause to increase organizational efficiency. So following steps must be taken by the ICCBS management to get the desired results.

n They must clearly distinct their academic and business related objectives; it will require the business re-engineering process after that ICCBS will enable to set its vision according to new requirements.

n The staff other than the academic purpose will be higher separately on regular basis, they must really aware about their purpose of hiring and their performances will be evaluated against their define job descriptions.

The ICCBS is comprising on both new and old technologies some of its new units are highly equipped with the new modern technology and gadgets. On the other hand some of its labs are working with the old technology. To increase the effectiveness 
of the research work the all old labs must be equipped with latest technology and to control the employee redundancy all the employees must be trained accordingly, the job rotation in this regard is the best tool to apply.

\section{RESEARCH FINDINGS}

This research is based on the on-going academic research work and explanatory to get an overview of the impact of quality human resource in health-care providing industries / organizations. Therefore, the research is conceptual in nature and exploratory method is being used to give account:

n The role and effectiveness of human resource management in general and the impact of new technology on human resource performance,

n The impact of good human resource management practices on the quality of healthcare service, also

n Discussed the factors that affect the performance of individuals as well as the healthcare providing organizations.

n Data and information are collected through the libraries, recognized journals both local and international. In other words, it is conceptual analysis in which taken into consideration mainly based on previous research.

Research describes that the Human resource, new technology (inputs) and organizational performance (output) has significant relationship. Both variables play significant role for the organizational performance. It has been reviewed from the past researches both variables have potential ability to put an impact on overall organization performance. Research also reveals that the medical practitioners without tools (technology) are less efficient and the tools (technology) without medical practitioners are useless. It has been also reviewed that the modern technological innovation in the field of medical sciences have minimize the importance of the role of the medical practitioners or human resources in the healthcare organizations/institutions because most of the medical equipments and gadgets has an ability to diagnose and provide information regarding the treatment with the help of patients inputs. There is no expert or specialize staff is required to operate these machines.

There is no doubt that new technological innovations have been replacing human with machines and that these machines are performing more accurately as compare to humans. But truth is that these machines are not completely autonomous and up to certain level depends upon the humans. They can only perform those which is built-in in to these and required modification with the human inputs. These innovations have also increased the demand of more skilled and qualified workforce in healthcare organizations. The human resource must be highly trained and must have an ability to operate the modern medical equipments and gadgets to get the accurate results from them.

It is true that machines in term of robots are performing more critical tasks e.g., operations and complex surgeries. But these all are not happening throughout the world only developed

\begin{tabular}{l|llll}
\hline 54 & Jan-June 2016 & Volume 14 & Number 1 & JISR-MSSE
\end{tabular}


countries are able to take advantage of these modern innovations. Developing countries are relying on the capability of the human resources. Managerial Grid system provides five different kinds of strategies to overcome the situation and choose the right combination to utilize the available resources to enhance the benefits.

There is no doubt that new technology has brought unemployment itself but on the other hand it creates new job opportunities for the skilled workforce at higher wages. To elaborate that which one plays more effective role in the overall organization performance requires an empirical research on the topic. One thing is evident Quality of Human Resource always does an impact on overall organizational performance.

It was found that HR practices are indirectly linked to overall outcomes of the health-care organizations or it can be easily say that the Human Resource Management plays an important role for the enchantment of organizational efficiency and maximizing output of the available resources.

Various key success factors emerge that clearly affect health care practices and human resources management. This research reveals how human resources management is essential to any health care system and how it can improve health care models. Challenges related to the health-care services are examined, with suggestions for ways to overcome these problems through the proper implementation of human resources management practices. Comparing and contrasting selected research studies allowed a deeper understanding of the practical and crucial role of human resources management in health-care organizations.

There is no tailor made HR model available which is acceptable universally for every organization. Organizations must choose the best HR model according to their requirements specifically considering the nature of business. But the research studies provide the information regarding the strategies that an organization can adopt within the available resources. These strategies could be labor intensive or technology intensive. It's all depends upon the organizations capability, if they have sufficient capital they can choose the technology intensive strategy through introducing new technology. In other case they can choose labour intensive strategy through investing in their Human Resource (employees) enhancing their capabilities to perform their duties in more effective and efficient manner. This can be done through training and motivating employees. This strategy also includes cost but as compare the technology it requires less investment. It is also described that the technology intensive strategy will also comprises the training cost of the employees due to the introduction of new technology.

Research also describes that the HRM practices of any organization does not put direct impact on client (patient) satisfaction. But they can increase employee satisfaction which can leads to the client satisfaction. The training activities of the HRM create the patients satisfaction, and leadership style of the organization leads to the job satisfaction of the employees.

Research study also describe that the High Performance Human Resource Practices (HPHRP) is very much related to the work environment. It is observed that the employees working in safe and healthy environment performs better than the employees with less safe environment.

Research study reveals that the HRM practices are not only the responsibility of the HR managers. The line and middle managers plays very crucial role for the implementation of HR policies and practices, so the coordination and communication between HR Manager

\begin{tabular}{llll|l}
\hline JISR-MSSE & Volume 14 & Jumber 1 & Jan-June 2016 & 55
\end{tabular}


and the Line managers must very clear and distinctive. Because the lack of communication for miscommunication will lead to an adverse effect on HR related practices.

\section{CONCLUSION}

The management of human resources is essential to enable the delivery of efficient and effective medical services and to achieve patient satisfaction, the study shows that human resources management has a strong impact on health-care quality, and most of literatures show the importance of human resources management to achieve the goals of health-care providing organizations, and emphasize to develop the performance of hospital staff and nurses through periodic training in order to improve the quality of health-care service, also a strong, well-motivated and highly trained medical profession is critical to the success of the health-care reform. The practices of human resource management are very important in health sector and modern hospitals need alternative approaches for practicing HRM successfully. The senior management in hospitals should have a clear strategic direction and clear objectives to improve the management of employees and staff in the hospital.

The HR of health-care providing organizations can be dividing into two categories:

I) Medical Staff (Doctors, Physicians, Practitioners, other Paramedical Staffs)

II) Non-Medical Staff (Administrative staff, Marketing, HR, Accounts, etc.)

Proper management of all human resources is critical in providing a high quality of health care. A refocus on human resources management in health care and more research are needed to develop new policies. Effective human resources management strategies are greatly needed to achieve better outcomes from and access to health care around the world.

\section{RECOMMENDATIONS}

The Reviewing of previous literatures that cover the field of HRM in hospitals and health organizations shows the need for further improvement in any health organization.

However, this study sets the following recommendations:

1. Setting a strategy for human resources management according to the requirements of new era.

2. Before introducing a new technology in an organization, inputs from the workforce must be acquire by the management.

3. To increase the human resource out put both intrinsic (variable pay system) and extrinsic (highlighting and appreciating the good performers) rewards must be used by the management.

4. Organization culture plays very important role in adaption of new technology. Organization with clear distinction of authorities and powers among the different levels of employees will adapt changes quicker than others. Because team work plays a vital role in the implementation of change process. 
5. The development of personnel management process must be continued to align the organizational workforce according to the new technological requirement.

6. Engage the staff of the hospital in the larger functional tasks in order to give them more confidence in the health institution in which they work.

7. Continuous development and training of staff performance.

8. The need to measure the performance of the manager of human resources department in the hospital before starting performance development process, and these measures include (leadership ability, self-qualification, risk management, strategic thinking, decision-making, innovation, management experience, and communications)

9. The aptitude of the employees is not enough to perform a task effectively. Workers with the right aptitude and attitude will become more productive.

\section{REFERENCES}

Anson BR, 2003, Taking charge in a volatile health care marketplace, Human Resource Planning, 23(4):21-34.

Avima Ruder (1963). An impolite interview with Paul Krassner, in The Realist, n. 41, June 1963 , p.24

Barnard C. -1948 Organization and Management. Harvard University Press.

Baldrige Criteria: http://www.baldrige21.com/Baldrige\%20Model.html

Baltimore, Maryland, Centers for Medicare and Medicaid Services: Medicare and You, 2006 http://www.medicare.gov/publications/pubs/pdf/10050.pdf.

Blake R.R.And Mouton J.S.-1985. The Managerial Grid III. Hogan Page.

Blauner R.-1964 Alienation and Freedom-the) Factory Worker and His Industry, III Chicago, University of Chicago Press.

Boselie et al 2005, Reviewed 104 articles linking HRM Practices and Organizational Performance published in major journals.

Bratton and Gold, 1999 Human Resource Management Theory \& Practice, 4th Ed.

Bright J.R.-1958 Automation and Management, Boston, Harvard Business School

Brown W. -1965 Exploration in Management. Harmondsworth, Elican, pp. 147-149 
CMS (Centers for Medicare \& Medicaid Services), Core Measure https://www.cms.gov/Medicare/Quality-Initiatives-Patient-Assessment Instruments/QualityMeasures/Core-Measures.html

Cooper M.H.-1974 Rationing Health Care, London Croom Helm

Culyer has put it, 'the utilization of health services has, on almost every indicator, increased continually since beginning.

David Ulrich, Human Resource Champions, 1996 Boston: Harvard Business School Press, Fombrun et al., 1984; Hendry and Pettigrew, 1986; Guest, 1987; Storey, 1989; Armstrong, 2000.

DHSS-1984 Report of Steering Group on Health Services Information: Implementation of Programme (HC(84)10, London, DHSS),

Dimick J.B. et al 2004, Compsoite measures for Profiling hospital or surgical morbidityright treatment (Christensen, C. M. 2009).

Donabedian's model: http://implementationcentral.com/ebponline/?page_id=340

Frederick Winslow Taylor (1856-1915), The Principles of Scientific Management (1911)

Halpern S. -1986, HMOs: Maintenance or Management. Health Serv. J.96 (5010), 1018-19

Harrison R. -1972, Understanding Your Organization's Character. Harvard Bus. Rev. 50 (3) $119-28$

How Does Human Resource Management Affect the Success of a Health Care Organization? by Dale Marshall, Demand Media

International Centre for Chemical\& Biological Studies (ICCBS), www.iccbs.edu

Joint Commission: https://www.jointcommission.org/standards_information/jcfaq.aspx

John R. Griffiths, The well managed healthcare organization.

Jones DA, 1996, Repositioning human resources, a case study. Human Resources Planning, 19(1):51-54.

Joint Learning Initiative. Human resources for health: overcoming the crisis. Cambridge: Global Equity Initiative, Harvard University; 2004.

Keenoy, T. and Anthony, P. (1992). 'HRM: metaphor, meaning and morality'. In Blyton, P. and Kenexa Research Institute (KRI), The Impact of Employee Engagement (Wayne, PA: Kenexa Research Institute, 2009).

Keith Sisson, Human Resource Management Journal, Volume 5, Issue 2, 1994; Legge K.

\begin{tabular}{l|llll}
\hline 58 & Jan-June 2016 & Volume 14 & Number 1
\end{tabular} 
1995, Human Resource Management: Rhetorics and Realities. Chippenham: MacMillan Business.

Kicab Castaeda-Mndez, Performance measurement in healthcare. http://www.qualitydigest.com/may99/html/body_health.html

Leavitt H. J. and Whisler T.L.-1958 Management in the 1980s. Harvard Business Review $36(6), 41-8$

Lewin K.-1951 Field Theory in Social Science, London, Harper \& Row

Lindholm C.E.-1969, The Sceence of Muddling Through. In: Ansoff H.I. (ed.) Business Strategy. Harmodsworth

Lloyd L. Bayars and Lesile W. Rue, 2006, Human Resource Management,

Malat J, Social distance and patient's ratings of health care providers, Journal of Health and Social Behavior 2001, 42:360-72

Management System," Harvard Business Review (January-February 1996): 76.Managing Human Resources. London, Edward Arnold

Mark A. Huselid, The Impact of Human Resource Management Practices on Turnover, Productivity and Corporate Profit, 1995, Vol. 38, no. 3, 655872.http://www.markhuselid.com/pdfs/articles/1995_AMJ_HPWS_Paper.pdf

Mc Lellan D-1970, Marx before Marxism. Harmondsworth, Penguin

Mc. Kinnies R. Collins S. Collins, K. \& Mathews 2012, Lack of Performance. The top reasons for terminating healthcare employees, Journal of Radiology Management 32(3): 44-47.

Method of coal-getting, Human Relations, Trist E. Op. Cit., P.84

Michael Hammer and James Champy, Reengineering the Corporation.

Michael Porter 1985, Competitive advantage, Creating and Sustaining Superior Performance.

Mumford E. -1973, Designing Systems for Job Satisfaction. Omega I, (4), 493-8.)

Nishii L.H. and Wright P.M. (in press), Strategic HRM and Organizational Behaviour Integrating Multiple levels of Analysis. Vernet: Verzuimmonitor 2010: Amsterdam; 2011

OECD Organization of Economic Cooperation and Development (www.oecd.com)

Paul Krassner, Harry Adler, Richard Claus, Laura Godofsky, Irwin Rosen, Carole Quinn. 
Pelling H-1963 A History of British Trade Unionism. Harmonds worth, Penguin, p.28

Prof. Dr. van Eenennaam, 'Value-Based Health Care supports health management, clinical management and health decision making.' http://www.vbhc.nl/what-is-value-basedhealthcare/concept-of-value-based-healthcare

Rajan A. and Cooke G.-1986, The Impact of Information Technology on Employment in the financial Services Industry. Nat. Wes. Bank Qurat. Rev. Augus issue, 21-35

Rajan A. and Cooke E. op. cit., p.31

Trist E.-1976 Critique of Scientific Management in terms of Socio-Technical Theory

Robert L. Mathis and John Harlod Jackon 2006, Human Resource Management, 11th Ed.

Robert S. Kaplan and David P. Norton, "Using the Balanced Scorecard as a Strategic

Russell K. Schutt, University of Massachusetts Boston, "Investigating the Social World-The Process and Practice of Research," 5th ed.

Taylor F.W.-1947 Scientific Management, London, Harper \& Row

The Importance of Human Resources Management to the Health Care System Academic journal article By Nica, Elvira

The world health report 2006: working together for health. Geneva: World Health Organization; 2006.

Thorley K. Personnel Management in the UK: An Urgent Case for Treatment

Turnbull, P. (Eds), Reassessing Human Resource Management Sage 233-55.

Trist E. and Bamforth K. -1951, Some Social and Psychological Consequences of the Longwall

Williams A. -1981 Organization Development. In: Cowling A.G. And Mailer C.J. B. (eds)

World Health Organization (2000). World health report 2000 - Health systems: improving performance.

World Health Organization Regional Office for Europe: Highlights on Health. Germany. Copenhagen 2004.http://www.euro.who.int/eprise/main/who/progs/chhdeu/system/ 20050311_1

World Health Organization World Health Report 2000 Health Systems: Improving Performance, Geneva. http://www.who.int.proxy.lib.uwo.ca:2048/whr/2000/en/whr00_ch4_en.pdf

World Health Organization World Health Report 2003: Shaping the Future Geneva. 2003.

\begin{tabular}{l|lll}
\hline 60 & Jan-June 2016 & Volume 14 & Number 1
\end{tabular}


http://www.who.int.proxy.lib.uwo.ca:2048/whr/2003/en/Chapter7-en.pdf

World Health Organization: World Health Report 2000. Health Systems: Improving Performance. Geneva 2000. http://www.who.int.proxy.lib.uwo.ca:2048/whr/2000/en/ whr00_ch4_en. Pdf

World Health Organization: World Health Report 2003: Shaping the Future. Geneva 2003 http://www.who.int.proxy.lib.uwo.ca:2048/whr/ 2003/en/Chapter7-en. Pdf

Zurn P, Dal Poz MR, Stilwell B, Adams O, 2004: Imbalance in the health workforce. Human Resources for Health, 2:13.

Asian Journal of Management Sciences \& Education ISSN: 2186-845X ISSN: 2186-8441 Print Vol. 3 No. 1, January 2014 Copyright (C) 2014 Leena and Luna International, Oyama, Japan.

International Journal of Health Policy and Management (www.ijphm.com)

Management in Health care by P.A. Riseborugh \& M. Walter. Publisher Wright, London Boston ISBN 0-72365-0862-8 